\title{
Optimization of Gap Current in Wire Cut EDM of P/M Cold Worked Tool Steel by Taguchi Method
}

\author{
Dr. G. Prasanthi ${ }^{1}$, D. Sudhakara ${ }^{2}$ \\ ${ }^{\text {I}}$ (Professor,Dept. of Mechanical Engineering, JNTUA College of Engineering, Anantapuramu,JNT \\ University, Anantapuramu, India) \\ ${ }_{2}^{2}$ (Associate Professor,Dept. of Mechanical Engineering, Siddarth Institute of Engineering \& Technology, \\ Puttur,JNT University, Anantapuramu,India)
}

\begin{abstract}
Wire electrical discharge machining process is an electro thermal modern machining process, is mainly used to cut complicate profiles of dies and mould of engineering materials. In the modern machine tool industry machining time is very important. The machining time is mainly depends upon the gap current. So that optimum conditions are very much required to cut the components in optimum time. The present research work mainly shows the optimization of process parameters of WEDM by Taguchi Design. ANOVA is used to study the effect of process parameters on machining process. The machining parameters investigated are pulse on time $(O N)$, pulse off time (OFF), Peak current (IP), Spark gap set Voltage(SV), Wire tension (WT) and Water pressure (WP). An $L_{27}$ orthogonal array has been used to plan and conduct the series of experiments and raw data and $S / N$ ratio are employed to analyze the influence of these parameters on gap current. The main intention is to find out the crucial factors and combination of factors influencing the machining process to achieve the best gap current. In this study MINITAB is used to find out the effect of each parameter on response characteristic and to predict the optimum setting of control parameters. In this study Powder metallurgical cold worked tool Steel is used for the experimental work and ELECTRONICA ULTIMA IF.
\end{abstract}

Keywords: WEDM, Gap current, Taguchi Method, Optimization of process parameters, ANOVA analysis

\section{Introduction}

Now days, there are far greater demands for higher precision in machining, ease of operation and increased longevity of both the parts as well as the machines that make them. CNC Wire Electrical Discharge Machining (WEDM) can satisfy and meet all these needs. The precision machining of complex geometries can easily be accomplished with minimal operations. Though many features are being provided by the WEDM manufacturers with their latest models; still there is no provision for setting the process variables that yields the best performances. Even a highly skilled operator with the state-of-the-art WEDM cannot achieve the optimal performances because the process involves a large number of variables and is complex and stochastic in nature. In order to get the right settings, it is common practice in industries to resort to trial-and-error method. For this reason, there is a heavy loss of materials, time and other resources occurring in the manufacturing industries. Moreover, the operators as well as the process engineers are usually not clearly understood the operation of WEDM to obtain the desired characteristics of the machined components. To meet the requirement of higher productivity with desired accuracy and surface finish, detailed investigations need to be carried out. It would be advantageous for the operators and process engineers, if tailor-made solutions are provided. The customized solutions serve as a ready reckoner to operate the machine with ease to achieve the specified requirements. In the present research study WEDM of Powder metallurgical cold worked tool steel has been considered. This material is considered for research work due to its both high wear resistance and ductility. Powder metallurgical cold worked tool Steel is however also very suitable for blanking and forming of Ultra High Strength Steel Sheet, these materials place high demands on the tool steel regarding abrasive wear resistance and ductility. Examples: Blanking and forming, Fine blanking, cold extrusion tooling, Powder pressing, Deep drawing Knives, Substrate steel for surface coating. Powder metallurgical cold worked tool steel is a chromiummolybdenum-vanadium alloyed steelwhich is characterized by very ductility, high abrasive- adhesive wear resistance and compressive strength, good dimensionalstability during heat treatment in service, good machine ability and grind ability. The main chemical composition of Powder metallurgical cold worked tool steel is C$1.4 \%$, Si- $0.4 \%$, Mn- $-0.4 \%$, Cr- $-4.7 \%$, Mo-3.5\% and Va-3.5\% and the balance is Fe. The density of Powder metallurgical cold worked tool steel is $7700 \mathrm{~kg} / \mathrm{m} 3$.Speeding and Wang (1997) performed experimental study on AISI 420 steel to optimize theprocess parameters in combos by modelling the method victimization ANN and characterized the WEDM machined surface by series technique. M.I.Gokler et.al. (2000) conducted experiments on Sodic Mark XI A500 EDW WEDM as machine and 1040, 2379 and 2378 steels as work piece materials in order to research the result of cutting and offset parameters on surface roughness in WEDM process. From the results it absolutely was complete that, the offset parameters doesn't have an effect on the surface roughness and 
same result with cutting parameters .If the thickness of the work piece will increase, the average feed rate decreases. Tusan et.al. (2003) used AISI 4140 steel as work piece material and Sodic A320/EX21 WEDM as machine tool conducted experiments to review the variations of cutting parameters with pulse on time, open circuit voltage, wire speed and dielectric fluid pressure. The responses thought-about during this study were surface roughness and cutting speed. From the results it absolutely was found that the cutting speed and surface roughness were will increase with increase in pulse on time, open circuit voltage and dielectric fluid pressure. Mathematical relationships between cutting parameters and cutting performances were developed by regression analysis method. The developed model was used in estimating performance characteristics. Based on Anova method, the open circuit voltage, pulse duration and wire speed were more effective on cutting speed. Whereas the dielectric fluid pressure was insignificant. In case of surface roughness, the open circuit voltage and pulse duration were more effective, wherever as fluid pressure and wire speed were ineffective. Sarkar et.al. (2005) conducted experiments on Electra SUPERCUT 734, SERIES-200 CNC WEDM machine victimization $\gamma$ titanium Aluminide alloy as work piece material so created a model they predict the cutting speed, surface finish and dimensional deviation as the operate of different WEDM parameters. Each surface roughness and dimensional deviation is independent of pulse off time. So pulse off time can be varied as per requirement to attain the higher stability and accuracy while not affecting the DD and surface finish considerably.They dete rmined the optimal method parameters byap plying unnatural optimization technique during which one performance characteristic was optimized considering different as constraints. Taweel et.al.(2005) uses AN ELEKTTA MAXICUT434 CNC WEDM as machine tool and INCONEL-601 as work piece, developed a mathematical model for correlating interrelationship of WEDM method parameters like peak current, duty factor, wire tension, water pressure and responses MRR,WR and SR uses RSM approach. Mahapatra et.al. (2006) allotted experimental studies on Robofil100 WEDM with D2-Tool Steel. They realize relationship between control factors and responses like metal removal rate and surface finish by exploitation non-linear regression analysis.GA was used to optimize the WEDM method with multiple objectives. Munna and Battacharya (2006) tried to optimize the method parameters of Super Cut -734 CNC Wire cut EDM machine with $\mathrm{Al} / \mathrm{SiC} \mathrm{MMC}$ as work piece material. The parameters of the WEDM process were pulse on time, pulse off time, peak current, wire feed rate, wire tension, spark gap set voltage and output responses were metal removal rate, gap current, surface roughness and spark gap(gap width).The experiments were planned as per Taguchi's L18 orthogonal array design. Analysis of variance and F-test were used to confirm the many machining parameters moving the machining performance. Mathematical models regarding the machining performance were established victimization Gauss elimination methodology. The open gap voltage and pulse on time were most vital parameters for dominant the metal removal rate. Wire tension and wire feed rate were most vital parameters for surface roughness, Wire tension and spark gap set voltage are the foremost vital parameters for dominant spark gap. The open gap voltage and gap current area unit the foremost vital parameters for dominant gap current. Chiang and Chang (2006) conducted experiments on Al2O3 particle reinforced material (6061 Alloy) with FANUC water spray wire cut discharge machine. The process parameters of the WEDM are on time, off time, arc on time, arc off time, servo voltage, wire feed, water flow and output response are cutting removal rate, surface roughness. The experiments were planned as per Taguchi's L18 orthogonal array design. The method parameters were optimized by gray relational analysis approach. From the results it had been concluded that on time, off time, time discharge and voltage have larger influence on the performance characteristics. Kanlayasiri et.al.(2007) used a Sodic A320 WEDM with ire electrode of 0.25mm diameter and DC53 was used as work piece material. He studied the effect of WEDM machining parameters pulse on time, pulse off time, pulse peak current, wire tension and surface roughness as response. The ANOVA technique was applied to seek out out the effect of method parameters on surface roughness. The ANOVA results were examined through residual analysis. Results from ANOVA showed that the surface roughness redoubled with the rise of pulse on time and pulse peak current. SauravDatta and Mahapatra (2010) conducted experiments on D2 tool steel with Robofil100 high preciseness CNC WEDM. The method parameters were discharge current, pulse on time, pulse frequency, wire speed, wire tension and dielectric flow rate and responses were MRR, surface roughness and kerf. The experiments were conducted supported Taguchi'sL27 orthogonal array and employed in improvement of method parameters in mixtures.

\section{Experimental Design}

In the present study six parameters i.e. pulse on time, pulse off time, peak current, Spark gap set Voltage, wire tension and water pressure were selected as input parameters during machining of work piece. The Experiments were conducted with distilled water as di-electric fluid and its conductivity is 20S, Servo feed is $2150 \mathrm{~m} / \mathrm{min}$, wire feed as $8 \mathrm{~m} / \mathrm{min}$ with a coated brass wire of $0.25 \mathrm{~mm}$ diameter as electrode. The six parameters were assigned values in 3 levels based on trial experiments. The preliminary experiments were conducted to select the range of values for machining parameters. 
Table 1: Process parameters their values and ranges

\begin{tabular}{|c|c|c|c|c|c|}
\hline \multirow[t]{2}{*}{ S. No. } & \multirow[t]{2}{*}{ Symbol } & \multirow[t]{2}{*}{ Units } & \multicolumn{3}{|c|}{ Levels } \\
\hline & & & 1 & 2 & 3 \\
\hline 1 & ON & $\mathrm{Mu}$ & 108 & 118 & 128 \\
\hline 2 & OFF & $\mathrm{Mu}$ & 47 & 55 & 63 \\
\hline 3 & IP & Amp & 11 & 13 & 15 \\
\hline 4 & SV & $\mathrm{V}$ & 18 & 43 & 68 \\
\hline 5 & WT & Grams & 2 & 5 & 8 \\
\hline 6 & WP & $\mathrm{Kg} / \mathrm{cm}^{2}$ & 8 & 11 & 14 \\
\hline
\end{tabular}

\section{Result Analysis}

27 experiments were conducted as per the $\mathrm{L}_{27} \mathrm{OA}$ to investigate the effect of GC on EDM wire cut machining parameters. The experiments were conducted as per the condition given in the Table 2 and the results were shown the same table with $\mathrm{S} / \mathrm{N}$ ratio. The results of raw data and $\mathrm{S} / \mathrm{N}$ data were plotted in the figure1 and 2. From the figure 1 and 2 it is revealed that, the GC is increases with increase in Ton and IP due to, with increase in Ton and IP the discharge current increases so that the gap current is also increase. The GC is decreases with increase in Toff, SV and WP. The effect of WT on the GC is not significant so that that is neglected. It is observed from Figures 3 and 4 that there is a slight interaction between pulse on time and peak current and there is very weak interaction between all the other process parameters in affecting the gap current since their responses at different levels of process parameters for a given level of parameter value are almost parallel.

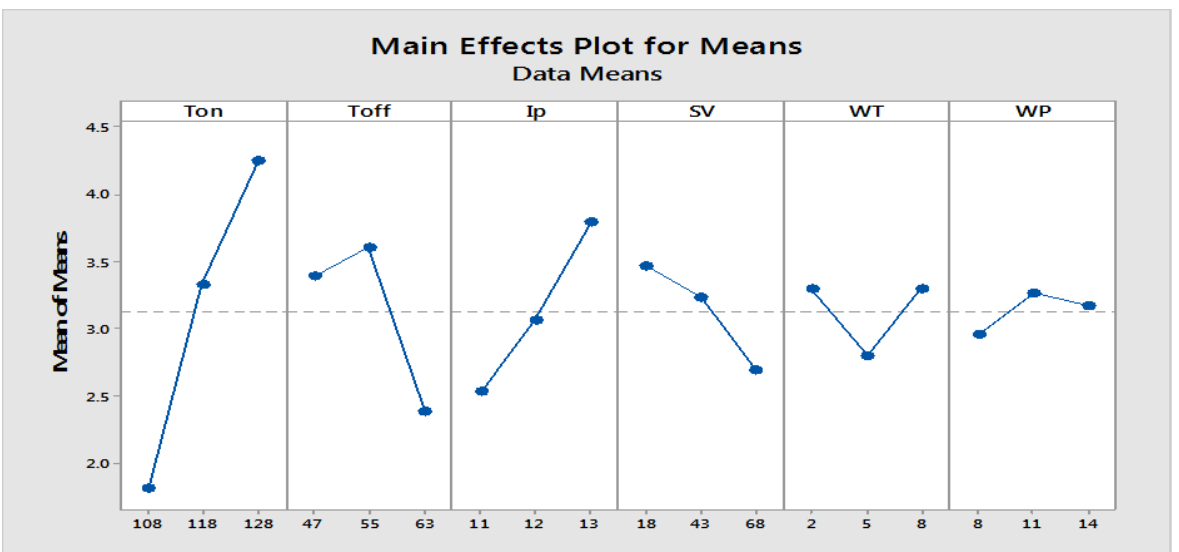

Fig. 1 Effects of Process Parameters on gap current (Raw Data)

Table 2: $\mathrm{L}_{27}$ Orthogonal Array (OA)

\begin{tabular}{|c|c|c|c|c|c|c|c|c|c|c|}
\hline \multirow[t]{2}{*}{ Exp. No. } & \multirow[t]{2}{*}{$\mathbf{O N}$} & \multirow[t]{2}{*}{ OFF } & \multirow[t]{2}{*}{ IP } & \multirow[t]{2}{*}{ SV } & \multirow[t]{2}{*}{ WT } & \multirow[t]{2}{*}{ WP } & \multicolumn{3}{|c|}{ Gap Current } & \multirow[t]{2}{*}{ S/N Ratio } \\
\hline & & & & & & & R1 & $\mathbf{R 2}$ & R3 & \\
\hline 1 & 108 & 47 & 11 & 18 & 2 & 8 & 1.46 & 1.45 & 1.45 & 3.247 \\
\hline 2 & 108 & 47 & 13 & 43 & 5 & 11 & 1.23 & 1.23 & 1.23 & 1.798 \\
\hline 3 & 108 & 47 & 15 & 68 & 8 & 14 & 2.47 & 2.47 & 2.48 & 7.866 \\
\hline 4 & 108 & 55 & 11 & 43 & 5 & 14 & 1.14 & 1.14 & 1.13 & 1.112 \\
\hline 5 & 108 & 55 & 13 & 68 & 8 & 8 & 1.17 & 1.17 & 1.16 & 1.339 \\
\hline 6 & 108 & 55 & 15 & 18 & 2 & 11 & 4.52 & 4.52 & 4.52 & 13.103 \\
\hline 7 & 108 & 63 & 11 & 68 & 8 & 11 & 0.89 & 0.88 & 0.89 & -0.915 \\
\hline 8 & 108 & 63 & 13 & 18 & 2 & 14 & 0.89 & 0.91 & 0.90 & -0.916 \\
\hline 9 & 108 & 63 & 15 & 43 & 5 & 8 & 2.49 & 2.50 & 2.49 & 7.936 \\
\hline 10 & 118 & 47 & 11 & 43 & 8 & 11 & 4.56 & 4.56 & 4.57 & 13.186 \\
\hline 11 & 118 & 47 & 13 & 68 & 2 & 14 & 3.34 & 3.35 & 3.34 & 10.484 \\
\hline 12 & 118 & 47 & 15 & 18 & 5 & 8 & 3.65 & 3.65 & 3.66 & 11.254 \\
\hline 13 & 118 & 55 & 11 & 68 & 2 & 8 & 1.74 & 1.75 & 7.74 & 6.488 \\
\hline 14 & 118 & 55 & 13 & 18 & 5 & 11 & 3.88 & 3.89 & 3.88 & 11.784 \\
\hline 15 & 118 & 55 & 15 & 43 & 8 & 14 & 4.19 & 4.20 & 4.18 & 12.444 \\
\hline 16 & 118 & 63 & 11 & 18 & 5 & 14 & 2.38 & 2.39 & 2.37 & 7.531 \\
\hline 17 & 118 & 63 & 13 & 43 & 8 & 8 & 1.97 & 1.95 & 1.96 & 5.845 \\
\hline 18 & 118 & 63 & 15 & 68 & 2 & 11 & 2.21 & 2.20 & 2.22 & 6.888 \\
\hline 19 & 128 & 47 & 11 & 68 & 5 & 14 & 2.88 & 2.88 & 2.87 & 9.178 \\
\hline 20 & 128 & 47 & 13 & 18 & 8 & 8 & 5.80 & 5.51 & 5.82 & 15.125 \\
\hline 21 & 128 & 47 & 15 & 43 & 2 & 11 & 5.26 & 5.27 & 5.26 & 14.425 \\
\hline 22 & 128 & 55 & 11 & 18 & 8 & 11 & 3.54 & 3.54 & 3.53 & 10.972 \\
\hline 23 & 128 & 55 & 13 & 43 & 2 & 14 & 6.09 & 6.09 & 6.09 & 15.692 \\
\hline 24 & 128 & 55 & 15 & 68 & 5 & 8 & 4.23 & 4.23 & 4.24 & 12.534 \\
\hline
\end{tabular}




\begin{tabular}{|l|l|l|l|l|l|l|l|l|l|l|}
\hline 25 & 128 & 63 & 11 & 43 & 2 & 8 & 2.19 & 2.19 & 2.20 & 6.822 \\
\hline 26 & 128 & 63 & 13 & 68 & 5 & 11 & 3.27 & 3.27 & 3.28 & 10.300 \\
\hline 27 & 128 & 63 & 15 & 18 & 8 & 14 & 5.14 & 5.15 & 5.13 & 14.219 \\
\hline
\end{tabular}

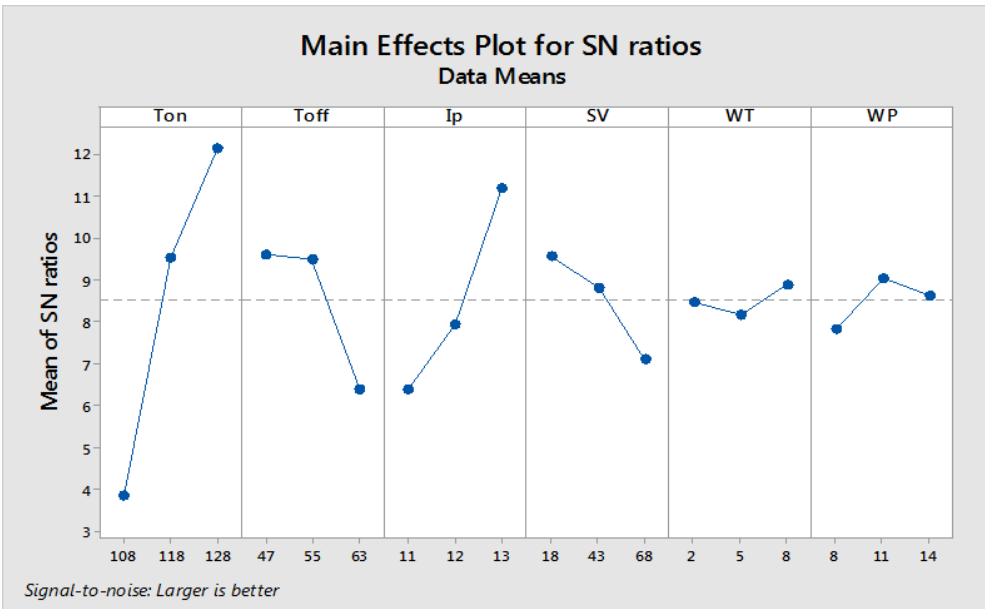

Fig. 2. Effects of Process Parameters on gap current (S/N Ratio Data)

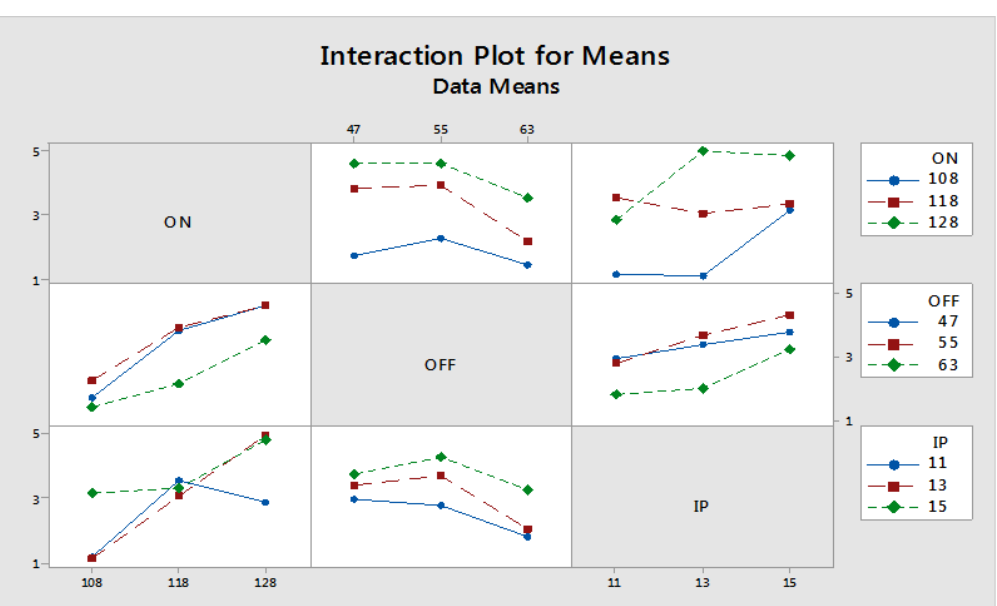

Fig. 3 Effects of process parameters Interactions on gap current (Raw Data)

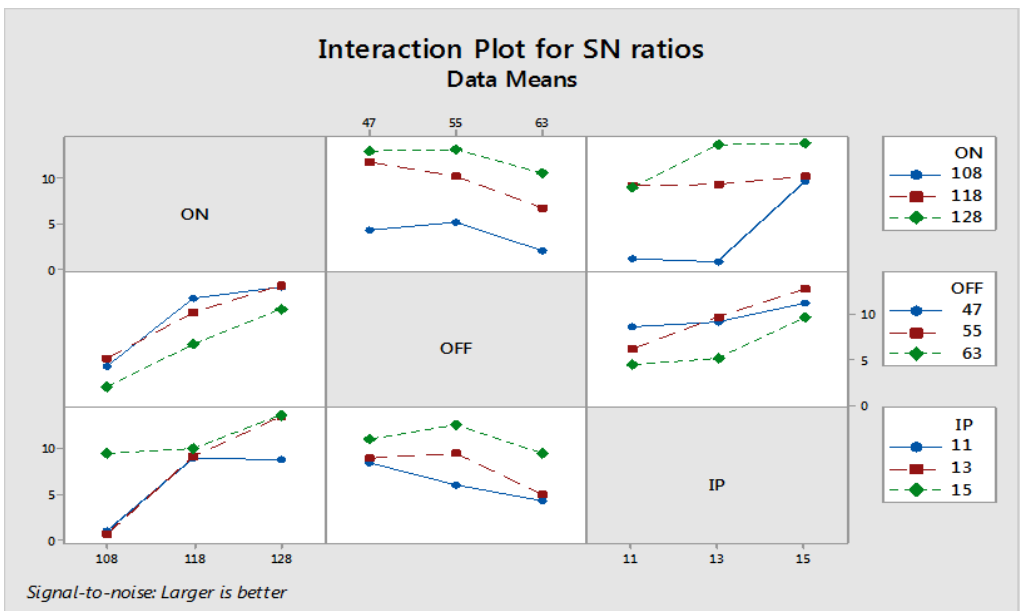

Fig. 4. Effects of process parameters Interactions on gap current (S/N Ratio Data)

\section{Selection of Optimum Levels:}

The ANOVA analysis is calculated to find the effect of machining variables on the GC. From the results of ANOVA it can be conclude that, the SV, WP and WT were considered as no significance parameters and eliminated based on the P-value in the pooled analysis tables 3 and 4 (Raw and S/N data). From the 
response tables it can be conclude that, The Ton is seems to be affecting more the GC based on the rank in the response tables. The IP and Toff were following the Ton in affecting the GC during wire EDM machining process. As the GC is applicable to Higher-is-Better type, from figure 1 it can be conclude that the 3rd level of Ton, 2nd level of Toff and 3rd level of IP provides maximum value of GC

Table 3. Pooled Analysis of Variance for Gap current (S/N Data)

\begin{tabular}{|l|c|l|l|l|l|}
\hline Source & DOF & Seq. SS & Adj. MS & F & P \\
\hline ON & 2 & 325.69 & 162.843 & 21.25 & 0.000 \\
\hline OFF & 2 & 59.96 & 29.980 & 3.91 & 0.037 \\
\hline IP & 2 & 107.88 & 53.940 & 7.04 & 0.005 \\
\hline Residual Error & 20 & 153.30 & 7.665 & & \\
\hline Total & 26 & 646.83 & \multicolumn{4}{|l|}{} \\
\hline
\end{tabular}

Table 4. Pooled Analysis of Variance for Gap current (Raw Data)

\begin{tabular}{|l|c|l|l|l|l|}
\hline \multicolumn{5}{|l|}{ Analysis of Variance for Means } \\
\hline Source & DOF & Seq. SS & Adj. MS & F & P \\
\hline ON & 2 & 27.543 & 13.7716 & 15.30 & 0.000 \\
\hline OFF & 2 & 7.291 & 3.6453 & 4.05 & 0.028 \\
\hline IP & 2 & 7.759 & 3.8795 & 4.31 & 0.033 \\
\hline Residual Error & 20 & 18.003 & 0.9002 & & \\
\hline Total & 26 & 60.596 & \multicolumn{4}{|l}{} \\
\hline
\end{tabular}

Table 5. Response Table for Signal to Noise Ratios

\begin{tabular}{|l|c|c|l|}
\hline \multicolumn{4}{|l|}{ Response Table for Signal to Noise Ratios } \\
\hline Larger is better & ON & OFF & IP \\
\hline Level & 3.827 & 9.618 & 6.388 \\
\hline 1 & 9.545 & 9.496 & 7.939 \\
\hline 2 & 12.141 & 6.398 & 11.185 \\
\hline 3 & 8.314 & 3.220 & 4.797 \\
\hline Delta & 1 & 3 & 2 \\
\hline Rank & \multicolumn{3}{|l}{} \\
\hline
\end{tabular}

Table 6. Response Table For Means

\begin{tabular}{|c|c|c|c|}
\hline Response Table for Means & \multicolumn{1}{|l|}{} \\
\hline Level & ON & OFF & IP \\
\hline 1 & 1.807 & 3.396 & 2.530 \\
\hline 2 & 3.325 & 3.611 & 3.062 \\
\hline 3 & 4.257 & 2.382 & 3.797 \\
\hline Delta & 2.451 & 1.229 & 1.267 \\
\hline Rank & 1 & 3 & 2 \\
\hline
\end{tabular}

The ranks indicate the relative importance of each factor to the response. The ranks and the delta values for various parameters show that pulse on time has the greatest effect on gap current and is followed by spark gap peak current and pulse off time in that order. As gap current is the "larger the better" type quality characteristic, from Figure 1, it can be seen that the third level of pulse on time (A3), second level of pulse off time (B2) and third level of peak current (C3), provide maximum value of gap current. The $\mathrm{S} / \mathrm{N}$ data analysis (Figure 2) also suggests the same levels of the variables (A3, B2, and C3) as the best levels for maximum gap current in WEDM process.

\section{Estimation of Optimum Response Characteristics}

In this section, the optimal values of the response characteristics gap current along with their respective confidence intervals have been predicted. The results of confirmation experiments are also presented to validate the optimal results. The optimal levels of the process parameters for the selected response characteristics have already been identified. The optimal value of each response characteristic is predicted considering the effect of the significant parameters only. The average values of the response characteristics obtained through the confirmation experiments must lie within the $95 \%$ confidence interval, $\mathrm{CI}_{\mathrm{CE}}$ equation. However, the average values of quality characteristics obtained from the confirmation experiments may or may not lie within $95 \%$ confidence interval, $\mathrm{CI}_{\mathrm{POP}}$ (calculated for the mean of the population).

\subsection{Gap current}

The optimum value of Cutting Rate is predicted at the optimal levels of significant variables which have already been selected as pulse on time (A3), pulse off time (B2), peak current (C3) and spark gap set voltage (D1) (Table 4 and Figure 1). The estimated mean of the response characteristic (CR) can be determined as: 
$\bar{T}=$ overall mean of Gap current $=\left(\sum \mathrm{R} 1+\sum \mathrm{R} 2+\sum \mathrm{R} 3\right) / 81=3.130$

$\overline{A 3}=$ Average value of Gap current at the third level of pulse on time $=4.257$ ampere

$\overline{B 2}=$ Average value of Gap current at the second level of pulse off time $=3.611$ ampere

$\overline{C 3}=$ Average value of Gap current at the third level of peak current $=3.797$ ampere

Substituting the values of various terms in the above equation,

Mean $\mu_{G C}=4.257+3.611+3.797-2(3.130)=5.19$ ampere

The $95 \%$ confidence intervals of confirmation experiments $\left(C I_{C E}\right)$ and population $\left(C I_{P O P}\right)$ are calculated by using the following Equations.

And

$$
\left.C I_{C E}=\sqrt{F_{\alpha}\left(1, f_{e}\right) V_{e}\left[\frac{1}{n e f f}+\right.} \frac{1}{R}\right]
$$

$$
C I_{P O P}=\sqrt{\frac{F_{\alpha}\left(1, f_{e}\right) V_{e}}{n_{e f f}}}
$$

Where, $\mathrm{F}_{\alpha}\left(1, F_{e}\right)=$ The $\mathrm{F}$ ratio at the confidence level of $(1-\alpha)$ against DOF 1 and error degree of freedom Fe.

$N_{e f f}=\frac{N}{1+(\text { DOF associated in the estimation of mean response ) }}$

$N_{e f f}=\frac{81}{(1+6)}=11.571$

$\mathrm{N}=$ Total number of results $=27 \times 3=81$

$\mathrm{R}=$ Sample size of confirmation experiments $=3$

$V_{e}=$ Error variance $=0.9002$ from table (2)

$f_{e}=$ error $\mathrm{DOF}=20$

$\mathrm{F}_{0.05}(1,20)=4.35$ So,

$C I_{C E}= \pm 1.282$ and,

$C I_{P O P}= \pm 0.582$

Therefore, the predicted confidence interval for confirmation experiments is:

Mean $\mu_{G C}-C I_{C E}<\mu_{G C}<$ Mean $\mu_{G C}+C I_{C E}$

$3.908<\mu_{G C}<6.472$

The $95 \%$ confidence interval of the population is:

Mean $\mu_{G C}-C I_{P O P}<\mu_{G C}<$ Mean $\mu_{G C}+C I_{P O P}$

$4.608<\mu_{G C}<5.772$

The optimal values of process variables at their selected levels are as follows:

Third level of pulse on time (A3) : $\quad: 128$ Machine units

Second level of pulse off time (B2) : : 55 Machine Units

Third level of peak current (C3) : : 15 Amperes

\section{Confirmation Experiment}

In order to validate the results obtained, three confirmation experiments were conducted for the response characteristics (Gap current) at optimal levels of the process variables. The average values of the characteristics were obtained and compared with the predicted values. The results are given in Table 6 . The values of gap current obtained through confirmation experiments are within the $95 \%$ of $C I_{C E}$ of respective response characteristic. It is to be pointed out that these optimal values are within the specified range of process variables.

Table 7. Predicted Optimal Values, Confidence Intervals and Results of Confirmation Experiments

\begin{tabular}{|l|l|l|l|l|}
\hline $\begin{array}{l}\text { Performance Measures/ } \\
\text { Responses }\end{array}$ & $\begin{array}{l}\text { Optimal Set of } \\
\text { Parameters }\end{array}$ & $\begin{array}{l}\text { Predicted Optimal } \\
\text { Value }\end{array}$ & $\begin{array}{l}\text { Predicted Confidence Intervals at } \\
\text { 95\% Confidence Level }\end{array}$ & Actual Value \\
\hline Gap current & A3,B2,C3 & $5.19 \mathrm{Amp}$ & $\begin{array}{l}3.908<\mu_{G C}<6.472 \\
4.608<\mu_{G C}<5.772\end{array}$ & 5.32 \\
\hline
\end{tabular}

\section{Conclusion}

The effects of the process parameters viz. pulse on time, pulse off time, peak current, spark gap set voltage, wire tension and water pressure on response characteristics gap current. The optimal sets of process parameters were obtained for various performance measures using Taguchi's design of experiment methodology. The summary results of predicted optimal values of the responses and their confidence intervals (both for confirmation experiment and population) are given as under.

\begin{tabular}{|l|l|l|l|l|}
\hline $\begin{array}{l}\text { Performance Measures/ } \\
\text { Responses }\end{array}$ & $\begin{array}{l}\text { Optimal Set of } \\
\text { Parameters }\end{array}$ & $\begin{array}{l}\text { Predicted Optimal } \\
\text { Value }\end{array}$ & $\begin{array}{l}\text { Predicted Confidence Intervals } \\
\text { at 95\% Confidence Level }\end{array}$ & Actual Value \\
\hline Gap current & $\mathrm{A} 3, \mathrm{~B} 2, \mathrm{C} 3$ & $5.19 \mathrm{Amp}$ & $3.908<\mu_{G C}<6.472$ & 5.32 \\
& & & $4.608<\mu_{G C}<5.772$ & \\
\hline
\end{tabular}




\section{Journal Papers:}

\section{References}

[1]. Speeding, T. A.Wang, Z.Q," Parametric optimization and surface characterization of wire electrical discharge machining process”, Precision Engineering, 20(1), 5-15.

[2]. Gokler, M. I., Ozanozgu, A. M "Experimental investigation of effects of cutting parameters on surface roughness in the WEDM process", International Journal of Machine Tools \& Manufacture, 40,1831-1848.

[3]. Tosun, N." The effect of cutting parameters on the performance of WEDM", KSME international journal ,vol.17, No.6, pp.m816824,2003

[4]. Sarkar, S., Mitra, S., Bhattacharyya, B. "Parametric analysis and optimization of wire electrical discharge machining of $\gamma$-titanium aluminide alloy”, Journal of Materials Processing Technology, 159, 286-294.

[5]. Hewidy, M.S., El-Taweel, T.A, El-Safty.M.F. "Modeling the machining parameters of wire electrical discharge machining of Inconel 601 using RSM”, Journal of Materials Processing Technology, 169, 328-336.

[6]. Mahapatra, S. and Patnaik, A. “Optimization of wire electrical discharge machining (WEDM) process parameters using Genetic Algorithm" Indian journal of engineering \& Material Science, Vol.13, pp. 494-502

[7]. Manna, A. and Bhattacharyya, B. "Taguchi and Gauss elimination method: A dual response approach for parametric optimization of CNC wire cut EDM of PRAlSiCMMC”, International Journal of Advanced Manufacturing Technology, 28, 67-75

[8]. Chiang, K.T., Chang, F.P," Optimization of the WEDM process of particle-reinforced material with multiple performance characteristics using grey relational analysis" Journal of Materials Processing Technology 180 (2006) 96-101.

[9]. Kanlayasiri, K., Boonmung, S., "An investigation on effects of wire-EDM machining parameters on surface roughness of newly developed DC53 die steel", Journal of Materials Processing Technology, 187-188, 26-29.

[10]. Sauraw D., Mahapatra S.S.,"Modelling simulation and parametric optimization of Wire EDM process using response surface methodology coupled with grey-Taguchi technique", International journal of engineering, science and Technology, Vol. 2, No.5, pp.162-183.

Books:

[11]. Ross, P.J, “Taguchi techniques for Quality Engineering”, McGraw-Hill Book Company, New York

[12]. Roy, R.K. "A primer on Taguchi method", Van Nostrand Reinhold, New York.

Thesis:

[13]. Kumar, P. “Optimization of process variables affecting the quality of Al-11\%Si alloy castings produced by V-process", Ph.D. Thesis, University of Roorkee, Roorkee.

[14]. Rohit Garg "effect of process parameters on performance measures of wire electrical discharge machining", Ph.D. Thesis, National Institute Of Technology, Kurukshetra 